\title{
The Trade Market of Meat, Slaughterhouses in Albania
}

\author{
Msc.Raimonda Ajdini Ph.D Henerieta Themelko Msc.Ilir Ajdini \\ P.G. Student, Department of Economy and Agribusiness, Agricultural University of Tirana, Tirane,Albania \\ Assistant Professor, Department of Economy and Agribusiness , Agricultural University of Tirana, \\ Tirane,Albania
}

\begin{abstract}
Slaughterhouses are an important element in the management of meat product in Albania, such as the study on the functioning of their form is very necessary, we decided to analyze the steps pose passing meat product in Albania. As meat is a very important component of the Albanians diet, this study is based on data of customers for the product meat. We will treat terms of product quality meat that is, the standards applied in the marketing of this product. To reach these objectives, this study designed a conjoint choice experiment survey and collected primary data in the most populated cities of Albania. The meat industry and its marketers may benefit from this information by using it to strategically market their meat to different groups. This study refers to the informality that occurs mainly in meat products in Albania, especially for the district of Tirana, specifically the Tirana-Kavaja area.The study will encourage meat shops or slaughterhouses not to be part of the informality that we slaughter until the sale to the consumer. The relevance of the research lies in the way the meat product is traded.
\end{abstract}

Keywords: Classification, Data Mining, Machine Learning, Predictive analysis, Social Networking Spam, Spam detection.

DOI: $10.7176 / \mathrm{JESD} / 10-18-02$

Publication date:September $30^{\text {th }} 2019$

\section{INTRODUCTION}

Albania has been, is, and will remain for years a country where agriculture will play a very important role. Currently agriculture makes up about 31\% of GDP (MoAFCP 2012). Therefore it is important to consider agriculture in any of the country's strategic planning. Despite the importance of agriculture for the national economy, Albania is a net importer of agricultural products. The ratio of exports to imports in total is 1:8, with the value of total import of meat products in 2012 at 15,900,890 Euros (MoAFCP 2015).

However, in the process of approximation to the European Union (EU), Albania seeks potential export opportunities to EU and international food markets. Meat is among the traditionally produced agricultural goods in Albania. The dairy industry, and along with it meat collection system, are still in the course of modernizing structures and technologies. In the late 1990s, the first private slaughterhouses plants were established in different regions of the country.

Businesses operating in informality are able to avoid taxes and rules but suffer from the inability to effectively enforce contracts (as the business is operating illegally) and may give up formal lending markets.

While it is clear that this phenomenon exists, a standard definition of the informal sector is not found in the literature. However, there are numerous definitions used in different studies.

I would use the definition (Feige, 1990), according to which an activity is considered to be part of the informal economy or informal sector if this activity does not "comply with the established rules" present in the formal economy.

This means that the informal economy can only be defined in a particular context of the institutional structure surrounding it.

In recent years, scholars have shown interest in studying informal economy in many countries. This has come as a result of the causes and implications of policies related to the informal economy. Informal economy is difficult to measure because in nature it is a hidden economy. Macroeconomic methods help to calculate this part of the economy indirectly.

The authors (Schrage, 1984) and Thomas (1992) have defined the informal economy as "A set of activities that are legally subjected to taxation but are not declared as commercial legal activities and are not included in the value of national income or that are partially included in GDP "

In the literature of recent years and the IMF, the definition is accepted that in economies that are involved in bribery and corruption, economic initiatives are distorted as officials, governors, and private individuals are deferred to pay smaller portions of public spending from which public good is offered.

Consequently, the government collects fewer revenues that lead to lower public investment and increase the poverty and inequality of citizens.

It has always been assumed that the informal sector existed but was not deliberately studied until 1970 when economic events in the US and Europe allowed the researchers to consider how uneconomic economic activity is. Since then, the informal economy has been in the hands of economists, but relatively little progress has been made 
in its understanding. The importance of the informal sector lies mainly in its potential impact on economic policy.

Policy makers have little choice, they have to believe that the economic measurements and statistics provided to them by economists are accurate and the policies are formulated in this way on the basis of this information.

However, the informal sector potentially undermines the accuracy of this information, as informal economic activity, by definition, is not included in traditional economic indicators, and may therefore lead policymakers to make the wrong decisions.

Understanding the factors which may significantly influence household consumption is important in the planning of slaughterhouses, processors and manufacturers. Consumers' responses to changes in price and nonprice factors are basic to an economic analysis of almost all the policy decisions related to industry or government programs. Forecasting the future direction of household consumption, and how that direction might be modified through industry efforts or by national programs and policies, requires information on the relationships among prices, incomes, household characteristics and consumer demand. This study focuses on households as consuming units, explains and analyzes their purchasing behavior for dairy products.

The aim of this study is whether Albania has overtaken slaughters that meet European standards, as is the amount of trade of meat products in Albania. In other words the study tries to find out how different slaughters consider different attributes of meat, when they buy the product. From these differences we can than determine the market segmentation toward this.

\section{SIGNIFICANCE OF THE SYSTEM}

The paper mainly focuses on identifying the current situation in the meat industry in the region of Tirana,identifying factors influencing informality referring to categories, Farmers / Breeders, meat / slaughter industry, consumers, makers. The study of literature survey is presented in section III, Methodology is explained in section IV, section V covers the experimental results of the study, and section VI discusses the future study and Conclusion.

\section{LITERATURE SURVEY}

Tirana Region lies in the central part of Albania at an altitude ranging from several meters above sea level up to 1828 meters. the highest peak is represented by mountain . The county has an area of $1,654.63 \mathrm{~km}^{2}$. In its western part there is a coastal line with the Adriatic Sea. The length of the coast line is $33 \mathrm{~km}$, while in the north it is bordered by the district of Durres, northeast with Dibra, southeast of Elbasan, and in the south by the district of Fier.

The Tirana District Relief is a diversified combination of mountainous areas with lowland areas and coastal areas. There are some rivers and lakes in Tirana's territory. The main rivers that describe the territory of the region are the Erzen, Iege, Shkumbin and Tirana River River, which also describes the city of Tirana with its branch called Lana River. In Tirana, the lakes are artificially man-made: the artificial lake of Tirana, Lake Kodër-Kamëz, Farkë Lake, Tufina Lake. Lakes and rivers create a diverse landscape and constitute a potential for recreational and recreational facilities.

Tirana Region consists of two districts, Tirana and Kavaja districts. In the district of Tirana there are three municipalities of Tirana Municipality, Municipality of Vores, Kamza Municipality and Kavaja District have two municipalities of Kavaja Municipality and Municipality of Rrogozhina. In the district of Tirana there are 29 administrative units. The average altitude of the Tirana field is $521 \mathrm{~m}$, while the two highest mountains on which to lie are Dajti Mountain $1612 \mathrm{~m}$ and Mali me Gropa with $1828 \mathrm{~m}$.

Tax administration is also considered problematic in various reports of international organizations for the business climate in Albania in recent years, but at the same time it is an open business concern from direct meetings and responses through the on-line survey. Substantially different negative comments on administrative capacity, interpretation of legislation, frequent tax controls are underlined by business. These comments continue to be in coherence with the findings and recommendations of the Secretariat's Work Document "Proposals for Improving the Tax Control Process: Analysis in the framework of Improving Business Climate in Albania" presented at the October 5 meeting namely VAT, uncertainty and frequent changes of tax legislation, and relations with the Tax Administration as factors that can lead to informality.

Commercial entities or natural persons, because of their limited commercial activity, do not make cash payments for the circulation of their goods or services. These payments are regularly made through the second tier banks in the Republic of Albania, documenting all their receipts and / or payments.

Under these conditions, these businesses issue regular tax invoices (VAT format or simple tax invoice) but have not installed fiscal equipment, in accordance with the provisions of Article 55 of Law No. 9920 dated 19 May 2008 (as amended), which provides for the general rule in paragraph 1 as follows: "Taxpayers who conduct the flow of goods and services for which payments are not made through the bank are obliged to install and use the fiscal system through the use of fiscal equipment for registration of cash payments and for the obligatory issuance of a tax coupon ... "and following the legal details set forth in the Instruction of the Minister of Finance no. 24 
dated 02.09.2008 "On Tax Procedures" (as amended)Send feedback, History, Saved, Community.

This study does not pretend to exhaust all the issues on causes and measures for dealing with informality. It aims to stimulate debate and pave the way for other studies and prioritize concrete business-generated recommendations aimed at improving the business climate and enhancing fair competition.

As a result of the increase in the number of livestock and poultry feeders for the production of meat product, a chaotic situation has been created requiring a reorganization of public structures across the chain from livestock breeding to the concentration of live animal markets - livestock trading, transport, slaughter, reimbursement scheme / farmer sales scheme, standardization and categorization of slaughtered carcasses, collection of purchase price and meat sales as a result of promotion of the whole chain for the declaring of the number of the animals increased their matriculation and slaughter procedures through a reimbursement scheme that formalizes the animal and slaughter market and after the conditions of meat trade, guaranteeing the traceability, identification and regionalization through the farmer's farmer and the area.

Consequently, reorganizing and guaranteeing the product's characteristics (traceability), standardization of price and quality of meat through legal and organizational changes will bring significant results in reducing informality, meeting the standards and requirements for food safety (high rigor for public health ) in the whole chain of fresh meat products will consequently also increase fair competition.

The study of habits / consumer preferences (knowledge of quality standards and food safety) on fresh meat consumption as affecting informality and stimulates unrestrained competition this consumer behavior.

Also, the body of the institutions that control this chain is not focused: livestock farmers / livestock transport / livestock keeping / slaughter points / veterinary control of Caracas / meat control during slaughtering and treating passes through three institutions and they have different dependencies (director of fame, local government unit.

Referring to the increase of production / production in the fresh meat sector and the number of farmers who breed slaughter animals, an unstable and chaotic situation has been created, from which some hypotheses are expected to be verified by this study.

-Customers with different socio-economic characteristics have different approaches to informality.

- Informality is influenced by factors such as (credibility with the trader, especially in peri-urban areas).

-Certification of products positively affects consumers' willingness to pay.

\section{METHODOLOGY}

Based on the data gathered from this study as well as to make a realistic and comparative analysis

In order to realize the objectives and hypotheses of this study, we will collect information through face-to-face customer surveys of meat products.

Use of statistical models of emerging variables among variables of interest.

Descriptive analysis of the processing industry sector based on primary and secondary data.

Its main exhibits and descriptions

A sample size of 200 questionnaires made with customers of meat products in Tirana and Kavaja is considered a suitable size to provide reliable and reliable data for the meat product informality analysis. Interviews were conducted personally by myself, by occasional customers. Our questionnaire is mainly conducted in two areas, Tirana which includes (agricultural isnitut, block area, unit 11, kashar and durrës road) as well as the circle of kavaja, from where customers were selected to study our (sample). The data obtained in the tables below shows the descriptive data regarding the Albanian consumers' considerations of meat product informality and the modeling related to our sample.

Show by place of residence, sex and education

\begin{tabular}{|l|c|c|c|c|}
\hline \multirow{2}{*}{ Description } & \multicolumn{3}{|c|}{ Education } & \multirow{2}{*}{ Total } \\
\cline { 2 - 5 } & High & Medium & Low & $\mathbf{5 3}$ \\
\hline Location 1 & $\mathbf{1 1}$ & $\mathbf{2 1}$ & $\mathbf{2 1}$ & 21 \\
\hline Females & 2 & 6 & 8 & 32 \\
\hline Men & 9 & 15 & $\mathbf{2 0}$ & $\mathbf{1 4 7}$ \\
\hline Location 2 & $\mathbf{6 4}$ & $\mathbf{6 3}$ & 14 & 88 \\
\hline Females & 34 & 40 & 6 & 59 \\
\hline Men & 30 & 23 & $\mathbf{4 1}$ & $\mathbf{2 0 0}$ \\
\hline Total & $\mathbf{7 5}$ & $\mathbf{8 4}$ & & \\
\hline
\end{tabular}

Table 1

The table data, respectively, shows educational education of the interviewed customers in the two areas selected by us. Out of the 200 interviewees in total, 53 interviews included ( 21 women according to education, 2 have high education, 6 with secondary education and 13 with lower education, and 32 men with 9 , with higher education, 15 with education middle and 8 lower secondary education), and 147 interviews were conducted in the Tirana area where: 88 are women (34 of them with higher education, 40 with secondary education, 14 with lower 
education, and 59 are men where : 30 are with higher education, 23 with secondary education and 6 with lower education).

Show by place of residence, gender and number of working members

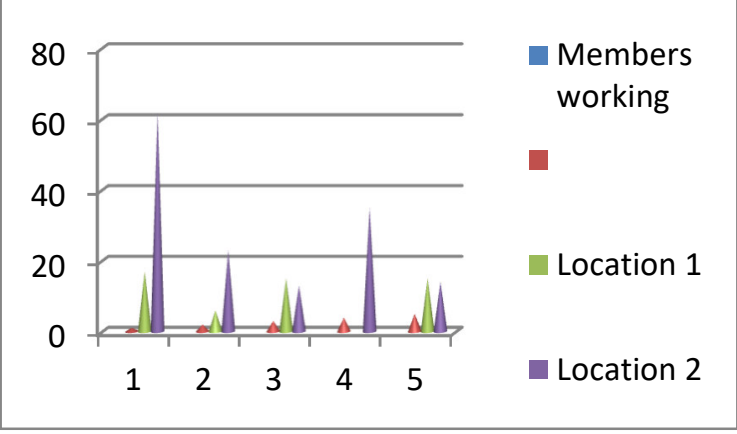

\section{Graf 1}

Graf 1 represents the cross-sectional data according to the place of residence, gender and number of members working from 200 completed interviews. then 17 women and men in the first zone have one member employed, 6 of the interviewed individuals have 2 employees, 15 interviewed individuals have 3 employees and 15 of them have 5 employees. While in the second zone, 62 including the interviewed women and men, there are 1 employed member, 23 of them have 2 employees, 13 of 3 employees 35 have 4 employees and 14 have 5 members employed. Show by place of residence, sex and consumption of meat product

\begin{tabular}{|c|c|c|c|c|}
\hline & \multicolumn{3}{|c|}{ Consumption of meat product } & \multirow{2}{*}{ Total } \\
\cline { 2 - 4 } & $\mathbf{2} \mathbf{~ k g}$ & $\mathbf{4} \mathbf{~ k g}$ & $\mathbf{7 ~ k g}$ & $\mathbf{5 3}$ \\
\hline Location 1 & $\mathbf{1}$ & $\mathbf{2 5}$ & $\mathbf{2 7}$ & 21 \\
\hline Females & 1 & 16 & 4 & 32 \\
\hline Men & & 9 & 23 & $\mathbf{1 4 7}$ \\
\hline Location 2 & $\mathbf{2 4}$ & $\mathbf{1 0 3}$ & $\mathbf{2 0}$ & 88 \\
\hline Females & 13 & 59 & 16 & 59 \\
\hline Men & 11 & 44 & 4 & $\mathbf{2 0 0}$ \\
\hline Total & $\mathbf{2 5}$ & $\mathbf{1 2 8}$ & $\mathbf{4 7}$ & \\
\hline
\end{tabular}

Table 2
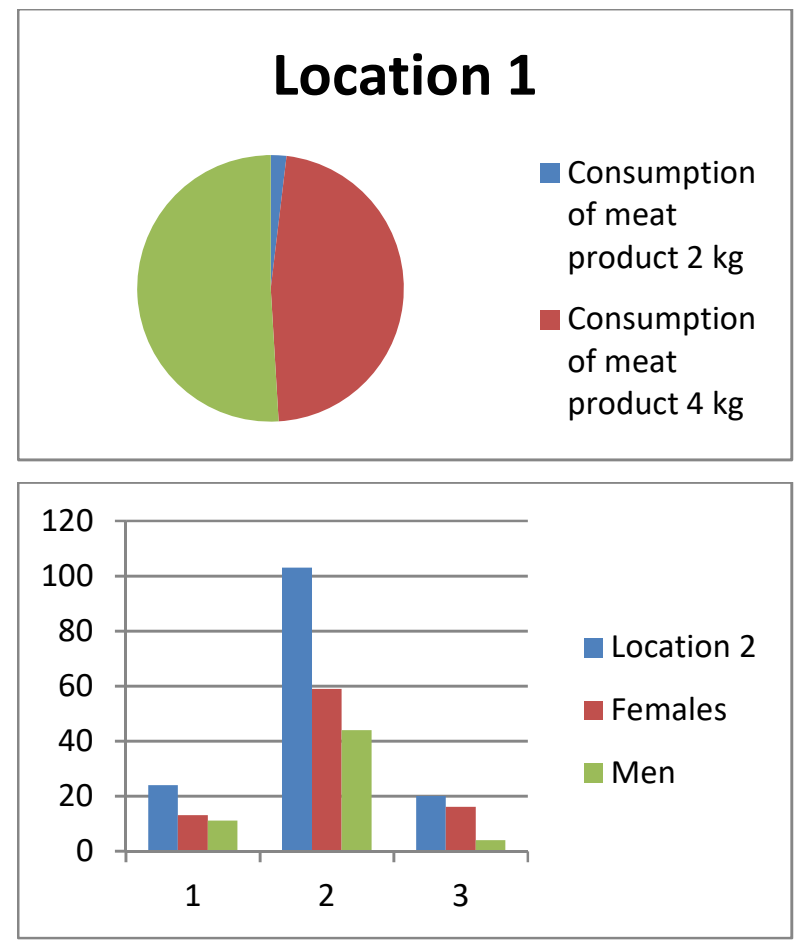

Graf 3 
Table 2 and Graf 2,3, shows the data of individuals interviewed regarding meat consumption by dividing them according to their sex and residence where they live. In the first area for the women's category we have: 1 woman consuming $2 \mathrm{~kg}$ of meat per month, 16 consuming $4 \mathrm{~kg}$ of meat per month and 4 consuming $7 \mathrm{~kg}$ of meat per month. While for men we have 9 who consume $4 \mathrm{~kg}$ of meat per month and 23 who consume $7 \mathrm{~kg}$ of meat per month. In the second zone for the category of women we have: 13 consuming $2 \mathrm{~kg}$ of meat per month, 59 consuming $4 \mathrm{~kg}$ of meat per month and 16 consuming $7 \mathrm{~kg}$ of meat per month. While for males we have: 11 individuals men consuming $2 \mathrm{~kg}$ of meat per month, 44 consuming $4 \mathrm{~kg}$ of meat a month and 4 consuming $7 \mathrm{~kg}$ of meat per month.

Trend of informality in the meat product

\begin{tabular}{|c|c|}
\hline \hline Agree & Number of interviewed customers \\
\hline 0 & 1 \\
\hline 1 & 56 \\
\hline 2 & 87 \\
\hline 3 & 44 \\
\hline 4 & 12 \\
\hline Totali & $\mathbf{2 0 0}$ \\
\hline
\end{tabular}

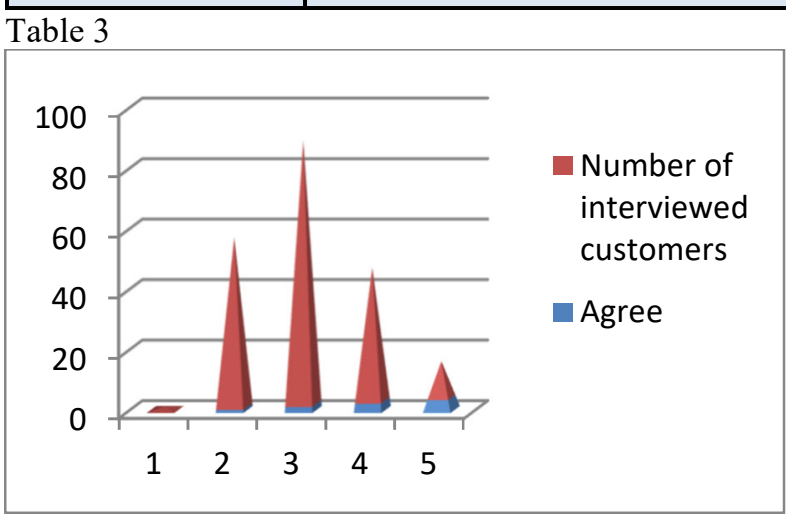

Graf 3

The above data represent the trend of informality for the meat product by estimating it from 0 to 4 . We notice from interviewed individuals that 1 is 0 agree, 56 of respondents agree with indicator 1 that there is informality in the meat product, 87 interviewees estimate with 2, 44 have evaluated with 3 informality and 12 interviewed have evaluated with 4 informality of the product of meat by 200 interviewed in total.

The Food Safety Trend in the last 5 years versus the trend of informality

\begin{tabular}{|c|c|c|c|c|c|c|}
\hline \multirow{2}{*}{ Informaility } & \multicolumn{7}{|c|}{ Food safety } & $\mathbf{5}$ \\
\cline { 2 - 7 } & $\mathbf{0}$ & $\mathbf{1}$ & $\mathbf{2}$ & $\mathbf{3}$ & $\mathbf{4}$ & \\
\hline 0 & 0 & & & & & 1 \\
\hline 1 & & 1 & 1 & 1 & 2 & 2 \\
\hline 2 & & & 2 & 2 & 3 & 3 \\
\hline 3 & & 3 & 3 & 3 & & $\mathbf{1 . 7}$ \\
\hline 4 & & 4 & & 4 & $\mathbf{1 . 8}$ & $\mathbf{2 . 2}$ \\
\hline Totali & $\mathbf{0}$ & $\mathbf{3}$ & $\mathbf{2 . 3}$ & & & \\
\hline
\end{tabular}

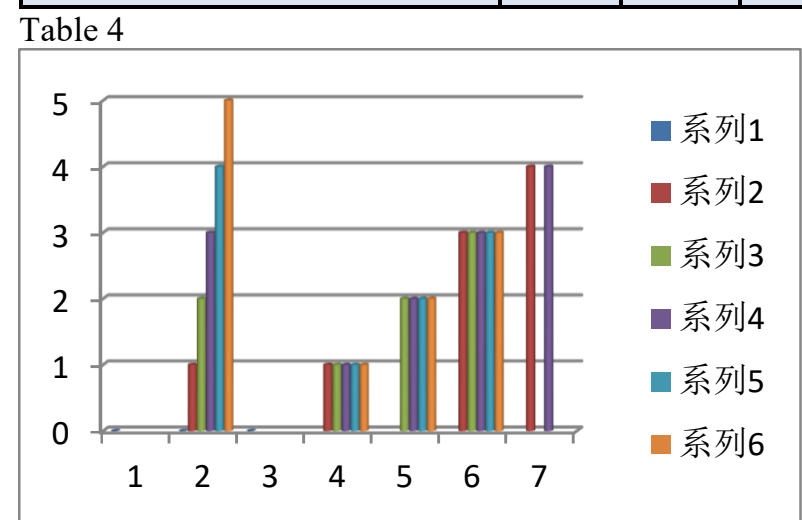

Graf 4 
Table 4 and Graf 4,shows data on food safety that are rated with 0 to 5 indicators. 1 customer interviewed rated 0 food safety, 4 interviewed customers rated 1 food safety, 34 interviewed customers rated it on 2 food safety, 80 interviewed consumers rated 3 food safety, 66 interviewed consumers rated 4 food safety and 15 of them out of the 200 interviewed estimated 5 food safety.

\section{CONCLUSION}

Dairy activities have a long tradition in Albania due to the favorable natural resources for dairy production. Meat producers must meet consumers' demand for meat when there is demand in order to remain competitive. Once we are able to clearly describe the existing demand for meat, a marketing strategy can be properly developed. In the meat industry remains the most important component in terms of production and also in consumption.

\section{REFERENCES}

- Ministry of Agriculture, Rural Development and Water Administration, www.bujqesia.gov.al

- Directorate of Agriculture Food and Consumer Protection

- Regional Agencies of the Ministry of Agriculture

- National Food Authority

- Veterinary Research Institute

- Agricultural University of Tirana Department Technology and Food

- University of Tirana Faculty of Natural Sciences 